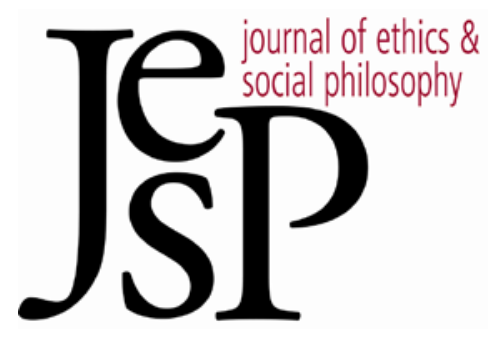

\title{
Humean Externalism and the Argument From Depression
}

By SteVEn SWARTZER 


\title{
Humean Externalism and the Argument from Depression
}

\author{
Steven Swartzer
}

$1 \begin{aligned} & \text { DOMINANT POSITION IN MORAL PSYCHOLOGY combines } \\ & \text { two independently plausible views: the Humean theory of motivation } \\ & \text { and motivational externalism. }{ }^{1} \text { Motivational externalism is the denial }\end{aligned}$ of "internalist" claims that motivational force is somehow "built in" or "internal" to moral judgment. ${ }^{2}$ The Humean theory of motivation, inspired by Hume's (1978/1888: 415) claims that reason is motivationally inert and is merely "the slave of the passions, and cannot pretend to any other office than to serve and obey them," holds that, whenever an agent acts, the motivational impetus for her action necessarily has its source in her desires. According to Humean externalism, moral motivation is the product of one's moral desires - the desire to be moral, perhaps ${ }^{3}$ - which are distinct from or "external" to her motivationally inert moral judgments. ${ }^{4}$

Humean externalism is an attractive picture. Many philosophers find the arguments in favor of externalism to be highly compelling. These arguments are generally framed around plausible descriptions of human agents that fail to be motivated in appropriate ways, given their moral outlooks. In particular, a number of externalists have drawn on examples of severely depressed or listless agents who lack moral motivation. By demonstrating that there is a gap between the making of a moral judgment and one's being appropriately motivated, these examples are meant to establish that moral judgments are not themselves effective sources of moral motivation. Some further motivational attitude is needed to fill the gap. The Humean theory dovetails nicely with these externalist arguments. Many externalists endorse some form of cognitivism about moral judgments, according to which moral judgment is a species of belief. ${ }^{5}$ On the Humean view, it should be no surprise that there is a gap between moral beliefs and motivation. Moreover, according to the Humean, desires can fill this gap in a way that suggests elegant explanations of both widespread moral motivation and motivational failures associated

\footnotetext{
1 Proponents of some version or another of this view include Foot (2002), Stocker (1979), Williams (1981), Brink (1986; 1997), Railton (1986), Smith (1994, ch. 4), Mele (1995; 1996; 2003), Svavarsdóttir (1999), Roskies (2003), Zangwill (2008a; 2008b) and Sinhababu (2009).

2 The labels "internalism" and "externalism" derive from Falk (1986).

${ }^{3}$ Humean externalists might choose to characterize the content of the relevant desires in a variety of ways. For our purposes, we will gloss over these differences. In particular, we will set aside the question of whether or not moral terms explicitly figure into the content of such desires.

${ }^{4}$ In calling this view "Humean externalism," I do not mean to imply that this was Hume's own view. This view is "Humean" only insofar as it endorses the so-called Humean theory of motivation.

${ }^{5}$ For the purposes of this essay, I will generally assume a cognitivist account of moral judgments as well, except when the context makes it clear otherwise.
} 
with severe depression. So to the extent that one finds the externalist arguments compelling, one might also be tempted by the Humean version of this view.

This essay argues that examples of severe depression offer no support for Humean externalism. If the argument based on depression is to undermine a philosophically important internalist thesis, it must make use of some unspecified general constraint on motivational states. However, at a reasonable level of abstraction, the assumption needed to complete the externalist argument is also likely to imply that even desires could not be motivational states. Thus, the argument from depression depends on an assumption that is incompatible with the truth of the Humean theory. Furthermore, the natural Humean responses to this anti-Humean argument turn out to be versions of strategies that, if successful, internalists could deploy in defense of their position. These responses are thus unlikely to be available to the Humean externalist. In short, at a reasonable level of abstraction, one of the key motivations for externalism undermines, rather than supports, the Humean theory.

\section{Internalisms and Externalisms}

In the opening line of The Language of Morals, R. M. Hare writes: "If we were to ask of a person 'What are his moral principles?' the way in which we could be most sure of a true answer would be studying what he did." Albeit somewhat overstated, Hare's observation is that we regularly express our moral outlooks through our actions. A student who thinks that cheating is wrong might decide not to copy answers from another's exam, though there is little chance of being caught. A philanthropist might reasonably explain her charitable activities by insisting that successful people have a responsibility to give back to their communities. When asked, an omnivore is likely to argue that there is nothing morally wrong with eating meat. That people generally try to live by their moral principles is supposed to be a perfectly mundane fact about our moral lives.

Internalists and externalists both typically accept that moral assessment is linked to motivation in important ways. Their dispute is over the precise nature of that connection. Though usually qualified, the paradigmatic internalist claim is that the presence of some appropriate level of motivation is a necessary condition for sincere moral appraisal. In the words of Gilbert Harman (1977: 33), "To think that you ought to do something is to be motivated to do it. To think that it would be wrong is to be motivated not to do it."' Formally, we might present this paradigmatic version of internalism as a strong modal thesis:

6 See also Brink (1986: 26), Svavarsdóttir (1999: 163), Roskies (2003: 52), Shafer-Landau (2003: 143) and Rosati (2006) for similar formulations of internalism. 


\section{MODAL INTERNALISM:}

Necessarily, if an agent judges that an action, $\Phi$, is right (good, best, obligatory, etc.) she will be motivated to $\Phi$; likewise, if she judges that $\Phi$-ing is wrong (bad, inferior, impermissible, etc.) she will be motivated to not- $\Phi .^{7}$

(MODAL INTERNALISM) has the following externalist counterpart:

\section{MODAL EXTERNALISM:}

It is possible for an agent to judge that an action, $\Phi$, is right (good, best, obligatory, etc.) while not being motivated to $\Phi$; likewise it is possible for an agent to judge that $\Phi$-ing is wrong (bad, inferior, impermissible, etc.) without being motivated to not- $\Phi .8$

(MODAL EXTERNALISM) is one way of characterizing a standard externalist thesis. But externalism is also frequently presented in slightly different terms, as a positive explanatory thesis about the source of moral motivation. According to this alternative characterization, externalism holds that motivation to act morally comes from something outside of or "external" to the agent's moral views. For instance, Thomas Nagel (1970: 7) describes externalism as holding "that the necessary motivation is not supplied by the ethical principles and judgments themselves, and that an additional psychological sanction is required to motivate our compliance." Moral judgments play a role in explaining moral action, but not as the source of motivation. One's moral principles indicate what compliance looks like, but something beyond those principles must generate the motivation to comply. More precisely, this alternative version of externalism endorses the following explanatory thesis:

\section{EXPLANATORY EXTERNALISM:}

Whenever an agent engages in some motivated action, $\Phi$, the complete explanation of her action must appeal to some psychological state, distinct from her moral judgments, that serves as the ultimate source of motivation to $\Phi$.

Humean externalists endorse this explanatory picture, adding that the "psychological sanction" must be supplied by a distinct passion or desire. According to Humeans, all action is the product of two different kinds of mental states. Motivational states determine our aims or goals, and have "pull" or "oomph" to "push" us toward achieving those aims - these are the sources of motivated action. Informational states, by contrast, simply offer a view about what the world is like - they lack motivational force of their own, but instead tell us how likely it is that possible actions would promote the ends determined by our motivational states. Humeans claim that only desires and other passionate states can play the motivational role; beliefs and other

7 Typically, this thesis is understood as a claim of conceptual necessity. However, this would still be philosophically significant as a claim of nonconceptual metaphysical necessity.

8 Shafer-Landau (2003: 145-46) and Rosati (2006) define externalism in this way. 
cognitive states play only the informational role. Moreover, on this view, a desire cannot be generated by any rational process (like reasoning) without some preexisting motivational state playing a role in generating it. ${ }^{9}$ It follows that the explanation of any rational action needs to appeal to some desire (or desires) as the ultimate source of motivated action. Humeans are thus committed to the following:

\section{EXPLANATORY HUMEANISM:}

Necessarily, whenever an agent engages in some motivated action, $\Phi$, the complete explanation of her action must cite one or more of her desires as the ultimate source(s) of motivation to $\Phi$.

We can understand why externalists might be attracted to (EXPLANATORY HUMEANISM). If some extra "psychological sanction" is needed to motivate compliance with one's moral principles, desire is a likely candidate for such a state. This explanatory view is present in David Brink's (1986: 31) systematic defense of externalist moral realism when he suggests that moral motivation is the product of "deeply seated and widely shared psychological trait[s]," such as sympathy and the desire "to comply (even) with otherregarding moral demands." In a later essay elaborating his externalist position, Brink (1997: 13-14) explicitly endorses the more general Humean explanatory framework:

[T] $]$ he motivation of all intentional action, including moral motivation, requires the existence of independent conative state or pro-attitudes. ... I believe that fairness requires me to keep my promise to you, even at a significant personal cost to myself. I want to be fair. So I keep my promise to you, even at some cost to myself. ... But the motivation for my action does involve my more ultimate desire to be fair. ... If I did not have this more ultimate desire or commitment, my moral belief would lead nowhere (or elsewhere).

This idea is echoed by Sigrun Svavarsdóttir's (1999: 161) view "that moral judgments need to be supplemented by a distinct conative state (desire in the broadest sense of that term) in order to play a motivational role [and] this conative attitude is not necessarily present in those who make moral judgments." ${ }_{10}$

9 This is one component of what Neil Sinhababu (2009: 465) refers to this as the "Desire Out? Desire In!" principle.

10 Others endorse similar views. For instance, according to Adina Roskies (2003: 52), "to prompt action, [a] moral belief or judgment must be accompanied by a corresponding moral desire, ... one which is only contingently related to the moral belief." Nick Zangwill (2003: 134) also accepts externalism, described as "the view that moral judgments have no motivational efficacy in themselves, and that when they motivate us, the source of motivation lies outside the judgment in a separate desire." (See also Zangwill (2008a: 91): "[A]re selfdirected moral judgments intrinsically motivating, as 'internalists' say? Or does their motivational force derive from a distinct desire, as 'externalists' say?") 
If we understand externalism in terms of a positive explanatory thesis, like (EXPLANATORY EXTERNALISM), we might see the debate between internalists and externalists as a debate about which of two competing explanatory pictures is ultimately correct. If so, then the proper contrast to (EXPLANATORY EXTERNALISM) is not (MODAL INTERNALISM), but an internalist claim about what kind of explanations for moral motivation are in the running. We could articulate the rival internalist picture in several ways, but the basic idea should be clear: Internalists think that, rather than arising from some supplemental psychological sanction, moral motivation springs either from within the moral judgment itself or from some psychological state that is not entirely distinct from judgment. This basic idea could be presented in various strengths. For our purposes, the following thesis provides an appropriate contrast with (EXPLANATORY EXTERNALISM), and offers a philosophically important version of internalism:

\section{MODEST EXPLANATORY INTERNALISM:}

Sometimes, when an agent engages in some motivated action, $\Phi$, the complete explanation of her action will appeal to her moral outlook itself as the ultimate source of motivation to $\Phi$.

Although (MODEST EXPLANATORY INTERNALISM) is consistent with (MODAl INTERNALiSM), it is also weak enough to be consistent with (MODAL EXTERNALISM). ${ }^{11}$ For one might accept that moral judgments are motivational states that motivate only contingently. ${ }^{12}$ However, (MODEST EXPLANATORY INTERNALISM) is not so weak as to be uninteresting. ${ }^{13}$ First, internalism is frequently thought to lend credence to noncognitivist views of moral

${ }^{11}$ It is also worth mentioning that (MODAL INTERNALiSM) (but not (MODEST EXPLANATORY INTERNALISM)) is consistent with (EXPLANATORY EXTERNALISM). For one might think that agents are necessarily motivated to act consistently with their moral principles, but that this motivation comes from some distinct psychological state that necessarily accompanies moral judgments. The possibility of such views has been noted by Mele (1996: 730), Svavarsdóttir (1999: 163) and Roskies (2003: 52), among others.

${ }^{12}$ Shafer-Landau (2003, ch. 5) apparently endorses a version of this view, holding that moral judgments are defeasibly motivational. However, his considered position is difficult to pin down. He (2003: 134-40) initially rejects the claim that moral judgments can be motivational in the same way that desires are - he holds that only "desires proper" motivate by being intrinsically motivating; moral judgments play a different, non-teleological motivational role. It is not clear exactly what that non-teleological role is, or whether it is compatible with moral judgments being sources of motivation. However, when discussing the defeasibility of moral motivation, Shafer-Landau appears to positively endorse the idea that moral judgments can be intrinsically motivational. For instance, he allows the possibility that "moral beliefs are intrinsically motivating, but their motivational efficacy is sometimes extinguished in unusual circumstances" and that "The near-perfect alignment of moral judgment and (some degree of) motivation can be explained by the intrinsic, prima facie motivating power of moral judgment" (2003: 157).

${ }^{13}$ Compare Roskies (2003: 52), who contends that only views that endorse (MODAL INTERNALISM) could properly be considered forms of internalism - or, at least, philosophically interesting forms of internalism. 
judgment. According to this line of argument, since moral judgments can be motivational in the way that ordinary beliefs are not, these judgments are more likely constituted by some noncognitive state. ${ }^{14}$ While these arguments are often depicted as relying on (MODAL INTERNALISM) as the key premise, it seems to me that (MODEST EXPLANATORY INTERNALISM) is enough to get the argument going. For the key idea seems to be that moral judgments can be independent sources of motivation in the way that normal beliefs are not - this could be true even if (MODAl InTERnAlism) is not. Second, if cognitivism about moral judgments and (MODEST EXPLANATORY INTERNALISM) are both true, this, too, would have significant philosophical implications for it would follow that (Explanatory HUMEANiSM) is false. Thus (MODEST EXPLANATORY INTERNALISM) is of philosophical interest independently of (MODAL INTERNALISM).

\section{The Argument from Depression Against Internalism}

In arguments against internalism, philosophers frequently portray severe depression or listlessness as a disorder that saps the motivational force of one's evaluative and moral outlooks. These arguments typically rely on plausible descriptions of deeply depressed subjects as having views about what would be morally good or otherwise valuable, while being unmoved by such considerations. Michael Stocker (1979: 744), for example, writes that:

Lack of [moral] desire is commonplace. Through spiritual or physical tiredness, through accidie, through weakness of body, through general apathy, through despair, through inability to concentrate, through a feeling of uselessness or futility, and so on, one may feel less and less motivated to seek what is good. One's lessened desire need not signal, much less be the product of, the fact that, or one's belief that there is less good to be obtained or produced, as in the case of a universal Weltschmertz. Indeed, a frequent added defect of being in such "depressions" is that one sees all the good to be won or saved and one lacks the will, interest, desire, or strength.

Alfred Mele (1996: 733-34) similarly describes a type of depression as "consist[ing] in the total absence of motivation to engage in activities of kinds that formerly were matters of deep personal concern," such as living up to one's moral responsibilities. ${ }^{15}$ Mele asks us to imagine a hypothetical agent, Eve, who suffered the unexpected loss of her spouse and children. Mele contends that it is conceivable that (1) this significant loss could trigger an episode of severe depression of the sort he describes, and (2) while in this depressed state, Eve might lack motivation to live up to her moral principles and to ful-

14 See McNaughton (1988: 20-23), Shafer-Landau (2003: 119-21) and Rosati (2006), for discussions of this type of argument.

15 See also Mele (1995: 403-4; 2003, ch. 5). 
fill her (self-recognized) duty to care for her sick uncle (Mele 1995: 403-04; 1996: 734; 2003: 111-17).

It is clear how Stocker's and Mele's description of depression constitute an argument for (MODAL EXTERNALISM). If these descriptions are coherent and plausible, it seems possible that an agent could make evaluative or moral judgments while not being appropriately motivated. What is less clear is how such descriptions are supposed to constitute an argument for (ExPLANATORY EXTERNALISM). For the modal version of the internalism/externalism debate is itself silent as to the potential sources of moral motivation.

Michael Smith (1994, ch. 4) is more explicit in his attempt to derive (EXPlanatory EXTERnAlism) from (MODAl ExTERnalism). According to Smith, those who accept that moral judgments can be sources of motivation are committed to the existence of "besires" - unitary states combining elements of belief and motivation. ${ }^{16}$ Smith (1994: 119) contrasts this with the view that these elements of belief and motivation "can always be pulled apart, at least modally" and "that it is always at least possible for agents who are in a belief-like state to the effect that their $\Phi$-ing is right to none the less lack any desire-like state to the effect that they $\Phi$." For Smith, if their belieflike and motivational aspects can be "pulled apart," these supposedly motivational judgments are not genuinely unitary besires but complexes of distinct attitudes: a desire-like attitude that is the source of motivation, and a belieflike attitude that is playing some other (presumably informational) role. Smith's derivation assumes a general test for determining whether a given unitary psychological state is capable of being a source of motivation:

\section{MODAL SEPARABILITY:}

If it is possible for an agent to be in some psychological state $\Psi$ (with some content suitably related to $\Phi$-ing) without being motivated to $\Phi$, then $\Psi$ cannot itself be an ultimate source of motivation to $\Phi$; when it exists, motivation to $\Phi$ must have its ultimate source in some attitude distinct from $\Psi$.

If (MODAL SEPARABILITY) is a good test for determining what states can be the ultimate sources of motivation, then motivational failures associated with severe depression seem to be inconsistent with (MODEST EXPLANATORY INTERNALISM).

\section{The Argument from Depression Against Humeanism}

Two facts about philosophical descriptions of severe depression are noteworthy. First, these descriptions typically emphasize that depression interferes with moral and evaluative motivation. Second, these descriptions typically presuppose a specific explanation for this interference: Stocker describes the agent's motivational failure in terms of her "lack" of or "less-

16 The term "besire" is owed to J. E. J. Altham (1986). 
ened" desire; Mele similarly portrays listlessness as the product of absent or weakened desires. Smith (1994: 135), too, claims that "the effect of ... depression is to remove [one's] desire." According to this proposed explanation, depression drives a wedge between moral or evaluative judgment and motivation by reducing the agent's desires to comply. More generally, depression eliminates motivation by eliminating desire.

These common descriptions of depression obscure two points. First, severe depression affects motivation generally, and is not limited to moral and evaluative motivation. ${ }^{17}$ Second, while depression might often eliminate an agent's desires or make her care less about things she previously cared strongly about, it is plausible that depression sometimes leaves the agent's goals, concerns, desires and commitments intact, but undermines their motivational efficacy. In other words, severe depression, in at least some forms, drives a wedge between the agent's conative states and motivation. ${ }^{18}$ Consider for example, how Caitlin Davies describes her experience with depression in the 2010 PBS television series, This Emotional Life:

Depression - it's not like having a bad day. It's just so much more than that - the exhaustion, the lack of focus, lack of motivation - it's just everything. ... Your body feels it. You feel down. You can't move. You can't get up and do what you want to do. And it doesn't matter how much you want to do something, you just can't. ... It's not like I want to watch TV all day or sit inside. It's like you want to go outside, you want to be with your friends, you want to be running around and you can't. It doesn't matter how much you want to, you can't. And it just sucks. It just really does.

Caitlin describes herself as lacking motivation despite wanting to do many things. What is especially interesting about Caitlin's self-description is that she twice insists that it does not matter how much she wants to do these things. A natural way to understand what Caitlin is saying here is that her depression does not undercut how much or how strongly she desires to engage in certain activities, it undercuts her ability to be motivated by those desires. According to this understanding, this is part of why depression can be so frustrating to those who experience it - in Caitlin's words, it "just really [sucks]" to lack the motivation necessary to successfully do things one very much wants to do.

Others who have suffered complete depressive breakdowns have described a similar phenomenon. Russell Goddard recounts one such experience:

17 In fact, there is some psychological evidence that depressed subjects primarily lose prudential motivation and retain more moral motivation than nonmoral motivation. For a discussion of this evidence, see Cholbi (2011).

18 It should be emphasized that, given how many distinct dimensions there are to depression, there is likely no single mechanism by which depression undermines motivation in all cases. For a discussion of many of these dimensions, see Solomon (2002). 
I knew that my son's wedding would be emotional ... and that anything emotional, good or bad, sets me off. I wanted to be prepared. I'd always hated the idea of electroshock therapy, but I went and had it anyway. But it didn't do any good. By the time the wedding came, I couldn't even get out of bed. It broke my heart, but there was no way that I could get there (Solomon 2002: 62).

It is most natural to think that, at the time of his son's wedding, Russell cared about attending and wanted to go. In fact, given that missing the wedding "broke [his] heart," it is natural to think that he cared quite strongly about this. Yet, as commonly happens to those with debilitating depression, Russell completely lacks motivation to pursue the ends he deeply cares about - he lacks motivation to take even the most basic steps, like getting out of bed. Once again, this is part of what is so frustrating about such experiences. That one is unable to engage in activities that one cares strongly about is part of why such situations are so heartbreaking. Indeed, this lack of motivation to do what one strongly cares about doing frequently reinforces and exacerbates one's feelings of hopelessness and despair.

This strikes me as a plausible understanding of what sometimes happens in cases of severe depression. However, this understanding poses a problem for those who would insist on too tight a connection between desire and motivation. In particular, this understanding gives us reason to doubt that being motivated to $\Phi$ is identical to desiring to $\Phi$, or that strength of motivation is, of necessity, identical to degree of desire. ${ }^{19}$ For it seems quite coherent to say that Caitlin and Russell strongly desire or strongly care about doing things that, because of their depression, they lack motivation to do. Whatever motivation is, it seems to be at least conceptually separable from desire.

What is of greater interest to me, however, is that, given that motivation and desire are conceptually separable in this way, this plausible understanding of depression also presents a challenge for Humean externalists who appeal to depression in support of their view. As we have seen, externalists sometimes argue against (MODEST EXPLANATORY INTERNALISM) by claiming that plausible descriptions of severely depressed agents lacking moral motivation, along with some general test along the lines of (MODAL SEPARABILITY), seem to rule out that moral judgments could be sources of motivated action. Intuitively, the argument is that the existence of depressed agents who fail to be motivated by their moral judgments suggests that we need to appeal to some distinct state to explain agents who are appropriately motivated. However, given that depressed agents sometimes lack motivation to satisfy even significant desires, goals, commitments and concerns, most (if not all) of the conative states that Humeans take to be sources of motivation fail this same test. For, as we have just seen, it seems possible that a severely depressed agent could have one of these attitudes without being appropriately motivated.

19 See, for instance, Mele (2003, chs. 6-7). 
Thus (MODAl SEPARABILITY) suggests that explanations of motivated action must appeal to yet some further attitude to serve as the ultimate source of the agent's motivation; desires themselves cannot fill that role. But if desires cannot be the ultimate sources of motivation, it would follow that (EXPLANATORY HUMEANISM) is false. Thus the motivation for externalism, combined with a plausible description of the psychologies of some depressed agents, seems to undermine the basic Humean thesis.

\section{Humean Responses}

Humeans can certainly say things in response to this argument. For instance, the Humean is free to reject (MODAL SEPARABILITY) if she wishes to do so. The challenge, however, is to offer a response that does not undermine the original motivation for (EXPLANATORY EXTERNALISM). This, I contend, is more difficult than it initially appears.

The most likely line of response is to insist that the anti-Humean argument rests either on a flawed conception of desire or on a flawed conception of motivation. On the one hand, some Humeans might be convinced that an agent who desires that $p$ is necessarily motivated to satisfy that desire. ${ }^{20}$ In the cases at hand, either Caitlin and Russell continue to be at least somewhat motivated to engage in the relevant activities, or they do not really desire to do so, after all. According to this line of thinking, the existence of motivationless desires is not really a conceptually coherent possibility.

On its own, this is an unsatisfactory response. For I find it difficult to see what is incoherent about our description of the cases. While some Humeans might claim that their concept of a desire just is the concept of a necessarily motivating state, the question is whether they are entitled to the claim that this is the ordinary concept of a desire - the same concept of desire that we use in normal contexts to explain motivated action. This is similar to the burden faced by defenders of (MODAL INTERNALISM): While they might insist that their concept of a moral judgment necessarily involves motivation, the externalist's plausible description of how depression sometimes works suggests that internalists are not entitled to the claim that the ordinary concept of a moral judgment is their concept. Unless the Humean says more to defend this move, insisting that our plausible description of the phenomenon does not describe a conceptually coherent possibility looks like mere stubbornness.

There is an even larger problem with this Humean response. Let us assume that, at the peak of his depression - when he "couldn't even get out of bed" - Russell lacked motivation to go to his son's wedding. If the Humean insists that her concept of a desire is the concept of a necessarily motivation-

20 Jonathan Dancy (1993: 2) contends that Humeans are already committed to this claim that desires are "guaranteed to motivate; they cannot exist without motivating [and] are essentially or necessarily motivating states." 
al state, then we must refuse to attribute any desire or other conative state to Russell that would (by assumption) falsely imply the existence of such motivation. For example, we must say that Russell had no desire to eat delicious cake and that he did not care about catching up with old family friends. We must also deny that Russell cared about his son's happiness and that he wanted to provide his son encouragement and support during this important life event. If we think that caring about one's happiness is necessary for loving him or her, we might even be forced to say that Russell did not really love his son. For we would normally explain one's motivation for attending a wedding in terms of attitudes like these, and the Humean response under consideration insists that the only states capable of playing that explanatory role are those that are guaranteed to motivate. So unless we want to insist that severely depressed agents who lack motivation lack all such conative attitudes, we cannot explain their lack of motivation in terms of their lack of desire.

Some Humeans might object that it is illegitimate to assume that Caitlin and Russell lack motivation. Perhaps, it might be suggested, our description of their situation illicitly assumes a phenomenological conception of motivation that the Humean could rightly reject. Or perhaps the Humean might question the evidential value of Caitlin's and Russell's self-conceptions by pointing out likely sources of error when describing one's own motivational situation. Such a Humean might insist that when one's motivation is so slight that there is little chance of effectively leading to action, it might be easy to mistakenly think of oneself as having no motivation whatsoever. ${ }^{21}$ For these reasons, the Humean might be skeptical that these cases provide us decisive examples of motivationless desires.

I agree that these examples are not decisive. However, this fact should give no solace to the Humean externalist. For if this move saves (EXPLANATORY HUMEANISM) from the anti-Humean argument, it should also rescue (MODEST EXPLANATORY INTERNALISM) from the corresponding externalist argument. The anti-Humean argument is not meant to rely on any controversial philosophical account of motivation. It does, however, place a great deal of weight on the claim that severely depressed agents sometimes lack motivation to do things that they would otherwise be motivated to do. But the same is true of the externalist argument from depression. The anti-Humean argument assumes that an agent's description of her own motivational psychology has evidential value, but the externalist makes use of this same evidence. If it is illegitimate to rely on the depressed agent's self-conception to determine what she lacks motivation to do, the externalist cannot rest her argument on examples of depressed agents who seem to lack motivation, either. It should be equally fair for internalists to question whether Eve and similar agents

21 To see how such an error theory might go, one could look to Mark Schroeder (2007: 9297), who provides a similar account to explain errors in judgments regarding what one has no reason to do. 
might be somewhat morally motivated, despite their self-conceptions to the contrary. After all, if our negative existential motivation judgments are unreliable, they are unreliable.

Mele (1995) comes close to recognizing the force of this challenge. But he, too, ultimately fails to meet it. He (1995: 399) holds that desires that the agent act in some way are necessarily motivational, and that only such desires are necessarily motivational - in his terms, all and only action-desires are essentially motivation-constituting states (or EMC states, for short). Immediately after citing listlessness as a reason to reject the idea that moral judgments could be EMC states, ${ }^{22}$ Mele (1995: 408) anticipates an objection similar to the problem I have posed:

Someone might contend that even if cognitivist moral ought-beliefs are not EMC attitudes, action-desires are on no firmer ground in this respect. It may be claimed, for example, that a jogger might desire to run another lap but be too tired even to try, so that this desire is not motivation-constituting.

Mele responds by claiming that for an agent to desire to $A, A$-ing must be "doxastically open" to her, in that she must not be convinced that she would fail to $A$ if she were to try. This, Mele (1995: 408) suggests, is the difference between attitudes that have motivational oomph and attitudes that do not: "an agent who takes his $A$-ing to be physically impossible might hope or wish that he could $A$, but he does not desire to $A .{ }^{23}$ If the jogger is too tired to try, her lack of motivation might be explained by the fact that she knows she

22 See also Mele (1996), for a more extensive discussion of the problem of listlessness.

${ }^{23}$ See also Mele (1995: 399): "desiring to $A$ does preclude [being convinced that one cannot $A]$. If I am convinced that I cannot travel faster than the speed of light, or change the past, or defeat the current heavyweight champion, then although I might wish that I could do these things, I do not desire to do them."

Mele's distinction between wishes and desires is problematic. In the context of the argument under discussion, Mele's view is most plausibly described as denying that wishes are unitary states - instead, they are composite states combining a desire-like element with a distinct doxastic element (the belief in inevitable failure). Moreover, despite Mele's claims to the contrary, it is most plausible that this desire-like element is really just a desire. On this interpretation, wishes are roughly desires-plus-beliefs-that-one-cannot-achieve-the-desiredresult-through-action. In other words, an agent's desire to $A$ counts as a wish to $A$ when $A$ ing is not "doxastically open" to her. To see this, suppose that Marty is initially convinced that time travel is impossible. Marty wishes that he could travel back in time, but does not desire to. Since he only wishes this, he is also not motivated to travel back in time. Now suppose that, at some later time, Marty comes to learn that Doc Brown is convinced that he has built a functional time machine. Though largely skeptical, Marty comes to give some positive credence to the possibility. How should we characterize Marty's conative attitude toward time travel at this later time? Given that time travel may now be within reach, there is nothing, on Mele's view, to preclude Marty's current attitude being an action-desire. So either a small shift in Marty's credences regarding the possibility of time travel necessarily generates a new desire in him, or that desire was really there all along - there alongside Marty's former belief that time travel is impossible. 
would not make it another lap, even if this is something that she wishes she could do.

Although Mele does not deal directly with the argument in the form that deals with severe depression, given their proximity to his discussion of listlessness, we might interpret his claims here as providing a response to this challenge. According to this response, depressed agents lack motivation because their depression is accompanied by a generalized pessimism about their ability to successfully navigate the world. Empirical psychological theories of severe depression based on learned helplessness might speak in favor of this hypothesis. Famously, after a dog learns that there is nothing he can do to escape a painful electric shock, he may cease trying to escape altogether, even in future situations where escape might be possible (Seligman and Maier 1967). Some psychologists have viewed this phenomenon as providing a model for motivational failures associated with severe depression. ${ }^{24}$ Depressed individuals suffer from something resembling learned helplessness, in part because they tend to see negative events as the product of pervasive and stable forces - especially the agents' own defects and faults (Klein et al. 1976; Seligman et al. 1979; Alloy et al. 1984). This account gives credence to the idea that depressed individuals have more of a feeling that failure is inevitable than do nondepressed agents. If such a feeling is incompatible with motivation, this might explain why Caitlin is not motivated to hang out with her friends and why Russell lacks motivation to attend his son's wedding.

Whether or not this explanation is credible as a general account of severe depression's influence on motivation, it does not provide a satisfactory response to the general challenge for the Humean externalist. This strategy seems to rescue (EXPLANATORY HUMEANISM) from the anti-Humean argument from depression. However, this comes at the cost of undermining the parallel argument against (MODEST EXPLANATORY INTERNALISM). For if severe depression carries an inevitable sense of failure, and if that explains the absence of motivation that accompanies this disorder, internalists should be able to say much the same thing. Thus externalists are hard pressed to explain why they can continue to embrace the Humean theory, while holding that motivational failures associated with severe depression present evidence for their view.

\section{Concluding Remarks}

I have tried to show that if motivational failures associated with severe depression provide strong evidence against motivational internalism, they provide similarly strong evidence against the Humean theory. The externalist argument from depression rests on something like (MODAL SEPARABILITY) some general principle about motivational states that can serve as a bridge

24 See, for instance, Akiskal and McKinney (1973: 24) and Miller and Seligman (1975). 
from plausible descriptions of depressed agents to the claim that moral motivation has its source in attitudes distinct from the agent's moral judgments. I have argued that this bridging principle is likely incompatible with a central Humean commitment. For, when coupled with other plausible descriptions of depressed agents, it implies that motivation has its source in attitudes distinct from the agent's desires. While there might be ways to resist this implication, the most plausible Humean responses are versions of strategies that internalists can deploy to resist the parallel anti-internalist argument. Thus the challenge for the Humean externalist is to respond to the anti-Humean argument from depression without unwittingly dismantling her parallel justification for externalism. Unless this challenge can be met, motivational failures associated with depression cannot be used as evidence in favor of Humean externalism. ${ }^{25}$

Steven Swartzer

University of North Carolina at Chapel Hill

Department of Philosophy \& Parr Center for Ethics

swartzer@email.unc.edu

25 I am grateful for the numerous conversations I have had about these issues with a number of philosophers. I would especially like to thank Brent Braga, David Chavez, Mark Decker, Janice Dowell, Luke Elwonger, David Faraci, Allison Fritz, Cullen Gatten, Leo Iacono, Clare LaFrance, Errol Lord, Tim Loughrist, Joe Mendola, Sruthi Rothenfluch, David Sobel, Adam Thompson, Mark van Roojen, Preston Werner and Vida Yao. I would also like to thank audiences at the University of Nebraska-Lincoln, the University of Nebraska Omaha and the University of North Carolina at Chapel Hill, as well as anonymous referees who provided me with valuable comments on earlier versions of this paper. 


\section{References}

Akiskal, H. S. and McKinney, Jr., W. T. (1973) "Depressive Disorders: Toward a Unified Hypothesis," Science 182(4107): 20-29.

Alloy, L. B., Peterson, C., Abramson, L. Y. and Seligman, M. E. P. (1984) "Attributional Style and the Generality of Learned Helplessness," Journal of Personality and Social Psychology 46(3): 681-87.

Altham, J. E. J. (1986) “The Legacy of Emotivism," in G. Macdonald and C. Wright, eds., Fact, Science and Morality: Essays on A. J. Ayer's Language, Truth and Logic, Oxford: Basil Blackwell, pp. 275-88.

Brink, D. (1997) “Moral Motivation," Ethics 108(1): 4-32. (1986) “Externalist Moral Realism,” Southern Journal of Philosophy 24: 23-42.

Cholbi, M. (2011) "Depression, Listlessness, and Moral Motivation," Ratio 24(1): 28-45.

Dancy, J. (1993) Moral Reasons, Oxford: Blackwell Publishing.

Falk, W. D. (1986) “'Ought' and Motivation," in W. D. Falk, ed., Ought, Reasons, and Morality: The Collected Papers of W. D. Falk, Ithaca, NY: Cornell University Press, pp. 21-41.

Foot, P. (2002) Morality as a System of Hypothetical Imperatives, in P. Foot, ed., Virtues and Vices, New York: Oxford University Press, pp. 157-73.

Gazit, C. and Dilbert, D. (2010) "Facing Our Fears" in C. Gazit and M. Robertson, producers, This Emotional Life, WGBH Educational Foundation/Vulcan Productions, Inc.

Hare, R. M. (1964) The Language of Morals, New York: Oxford University Press.

Harman, G. (1977) The Nature of Morality: An Introduction to Ethics, New York: Oxford University Press.

Hume, D. (1978/1888) A Treatise of Human Nature, Oxford: Clarendon Press.

Klein, D. C., Fencil-Morse, E. and Seligman, M. E. P. (1976) "Learned Helplessness, Depression, and the Attribution of Failure," Journal of Personality and Social Psychology 33(5): 508-16.

McNaughton, D. (1988) Moral Vision: An Introduction to Ethics, New York: Blackwell.

Mele, A. R. (2003) Motivation and Agency, New York: Oxford University Press. (1996) "Internalist Moral Cognitivism and Listlessness," Ethics 106: 727-53.

(1995) "Motivation: Essentially Motivation-Constituting Attitudes," The Philosophical Review 104(3): 387-423.

Miller, W. R. and Seligman, M. E. P. (1975) "Depression and Learned Helplessness in Man," Journal of Abnormal Psychology 84(3): 228-38.

Nagel, T. (1970) The Possibility of Altruism, Princeton: Princeton University Press.

Railton, P. (1986) “Moral Realism," Philosophical Review 95: 163-207.

Rosati, C. (2006) "Moral Motivation," in E. N. Zalta, ed., Stanford Encyclopedia of Philosophy (spring 2014 edition), http://plato.stanford.edu/entries/ moral-motivation.

Roskies, A. (2003) "Are Ethical Judgments Intrinsically Motivational? Lessons from 'Acquired Sociopathy'," Philosophical Psychology 16(1): 51-66.

Schroeder, M. (2007) Slaves of the Passions, Oxford: Oxford University Press.

Seligman, M. E. P and Maier, S. F. (1967) "Failure to Escape Traumatic Shock," Journal of Experimental Psychology 74(1): 1-9.

Seligman, M. E. P., Abramson, L. Y., Semmel, A. and von Baeyer, C. (1979) "Depressive Attributional Style," Journal of Abnormal Psychology 88(3): 242-47.

Shafer-Landau, R. (2003) Moral Realism: A Defense, Oxford: Clarendon Press.

Sinhababu, N. (2009) "The Humean Theory of Motivation Reformulated and Defended," Philosophical Review 118(4): 465-500.

Smith, M. (1994) The Moral Problem, Oxford: Blackwell.

Solomon, A. (2002) The Noonday Demon: An Atlas of Depression, New York: Simon \& Schuster.

Stocker, M. (1979) "Desiring the Bad: An Essay in Moral Psychology," Journal of Philosophy 76(12): 738-53. 
Svavarsdóttir, S. (1999) "Moral Cognitivism and Motivation," The Philosophical Review 108: 161-219.

Williams, B. (1981) "Internal and External Reasons," in B. Williams, ed., Moral Luck, Cambridge: Cambridge University Press, pp. 101-13.

Zangwill, N. (2008a) “The Indifference Argument," Philosophical Studies 138: 91-124. (2008b) "Besires and the Motivation Debate," Theoria 74: 50-59.

_ (2003) "Externalist Moral Motivation," American Philosophical Quarterly 40: 143-54. 